\title{
Current Status, and Correlates of Abortion among Rural Women of Gonji Kollela District, Northwest Ethiopia
}

\author{
Girum Meseret ${ }^{1}$, Molla Gedefaw ${ }^{2}$, Resom Berhe ${ }^{3}$, Adane Nigusie ${ }^{1}$ \\ ${ }^{1}$ Department of Public Health, Gonji Kolella Health Office, West Gojjam, Amhara Region, Ethiopia \\ ${ }^{2}$ GAMBY College of Medical Sciences, Bahir Dar, Ethiopia \\ ${ }^{3}$ Health Education Unit, Institute of Public Health, College of Medicine and Health Science, University of \\ Gonder, Gonder, Ethiopia \\ Email: mollagedefaw@yahoo.com, ${ }^{*}$ resom.berhe@yahoo.com
}

Received 25 February 2015; accepted 8 May 2015; published 12 May 2015

Copyright (C) 2015 by authors and Scientific Research Publishing Inc.

This work is licensed under the Creative Commons Attribution International License (CC BY). http://creativecommons.org/licenses/by/4.0/

(c) (i) Open Access

\begin{abstract}
Background: Evidences indicate that unsafe abortion is one of the most important causes of maternal mortality in Ethiopia. Ethiopia strives to curb maternal mortality. Hence, current data on abortion, and its correlates are required. Objective: To assess the prevalence and associated factors of abortion among women of reproductive age (15 - 49 years) in rural kebeles of Gonji Kolela District. Methods: A community based cross-sectional study was conducted among randomly selected 611 women in six rural kebeles of Gonji Kolela District, Northwest Ethiopia. A structured pre-tested questionnaire was used to collect data on socio-demographic and obstetric histories. The data were checked for completeness and cross-checked for accuracy and consistency. Result: The overall prevalence of abortion was $12 \%$ (10.9\% spontaneous and $1.1 \%$ induced). Of these, $12.3 \%$ of them had experienced abortion more than once. Most of abortion took place at home, no medical care. The most important predictor of abortion was educational status. Those women whose educational attainment was primary and above were 2.4 times more likely to experience abortion than those who were not able to read and write $(\mathrm{AOR}[95 \% \mathrm{CI}]=2.4[1.13-5.10])$. Most women attributed abortion to work overload. Conclusion: Abortion is high among rural women. Recommendation: Mechanism should be devised to educate the community about care to pregnant women. Why abortion is high among women who have visited school warrants further research.
\end{abstract}

"Corresponding author.

How to cite this paper: Meseret, G., Gedefaw, M., Berhe, R. and Nigusie, A. (2015) Current Status, and Correlates of Abortion among Rural Women of Gonji Kollela District, Northwest Ethiopia. Open Journal of Epidemiology, 5, 136-146.

http://dx.doi.org/10.4236/ojepi.2015.52018 


\section{Keywords}

\section{Unsafe Abortion, Family Planning, North West Ethiopia}

\section{Introduction}

Abortion is one of the most common obstetric events in the world being only second to childbirth. Maternal deaths due to unsafe abortions, the enormous cost to victims, families, health systems and nations are basically preventable problems. However, unsafe abortions are causing 50,000 to 100,000 deaths each year [1].

The World Health Organization estimates that as many as 20 million abortions each year are unsafe. Ten to fifty percent of the women that undergo unsafe abortion need medical care for complications [2]. Often women do not receive medical treatment soon enough. This delay puts their lives at risk and requires additional cost for treatment. Every year an estimated 36 to 53 million abortions are performed worldwide. Out of these, 20 million take place outside the health care system, and are performed by unskilled providers under unsanitary conditions or both [3]. In developed countries, mortality from legal abortion is about 0.6 per 100,000 procedures compared to 1000 deaths per 100,000 procedures in countries where the procedure is largely illegal [4].

It is African women, however, who are most likely to be affected when they undergo unsafe abortions. An estimated 3.7 million unsafe abortions are performed each year in Sub-Saharan Africa and about 23,000 Africans die from complications [5]. Maternal deaths attributed to abortion complications are about 35\% in both Kenya and Nigeria and about 28\% in Zimbabwe [6]-[8]. Similarly in a hospital in Zaire, around 60\% of all gynecological patients were reported to be abortion complications while in one hospital in Accra the comparable rate was over $50 \%$ [5].

Ethiopia has the fifth highest number of maternal deaths in the world. Only 27\% of Ethiopian women of reproductive age use modern contraceptives. Low levels of contraceptive use lead to high levels of unintended pregnancy, the root cause of abortion. Around $42 \%$ of all pregnancies are unintended [9]. Abortion is identified as one of the most important causes of maternal mortality in Ethiopia [10]. Abortion is not only a health problem. It has social, economic impact on individuals, families, and the nation at large [11].

Despite this, community based studies in Ethiopia are few, and the available institutional and community based data are old [12]-[19]. Hence, this study is timely, and the finding is crucial for program planning.

\section{Methods}

\subsection{Study Design}

A community based cross sectional study design was conducted with both descriptive and analytical components among women of reproductive age (15 - 49 years).

\subsection{Study Area}

The study was conducted in rural kebeles of Gonji Kolela District, from December 2012 to August 2013 out of 15 Districts of West Gojjam Zone. From north direction, the district is bordered by Dera and Yelmana Densa Districts, from east direction by Huletejuensie District, from south direction by Dega Damote and Qourite Districts and from west direction Yelmana Densa District [20].

Gonji Kollela District was a part of Yilmana Densa District before five years ago and it had been separated after the year 2006. The capital of the District, Addis Alem is $72 \mathrm{Km}$ far from Bahir Dar, capital of Amhara National Regional State. The total population of the District is estimated to be 107,392 of which (50.8\%) 54,519 are males and 52,873 (49.2\%) are females. From total population of the District only 6.9\% (7427) live in two urban kebeles and the rest in 24 rural kebeles. In the District there are 6 health centers, 10 private primary clinics, 2 private rural drug vendors and 26 health posts. Households and women in reproductive age living in the district were estimated to be 24,975 and 25,345 respectively [17] [18]. The District Health Office 2011/2012 annual report indicates that both antenatal and postnatal service coverage were above 85 percent. 


\subsection{Sample Size Determination and Sampling Method}

Sample size was determined by single population proportion formula using EPI INFO stat calc program with the assumption of $95 \%$ level of confidence, $4 \%$ of marginal error, and taking prevalence of $19 \%$ of women had abortions (14.3\% spontaneous and 4.8\% induced) [13]. Considering the design effect of two and $12 \%$ nonresponse rate, the final sample size became 622 women's in reproductive age group.

The study utilized simple random and systematic sampling methods. First, six kebeles ( $25 \%$ of the total) were selected randomly. Then from these kebeles using Kebeles’ HHs lists, HHs were selected systematically considering proportional allocation. From the selected HHs one study unit (women in reproductive age) from each $\mathrm{HH}$ was selected. In HHs which has more than one woman in reproductive age a woman was selected by lottery method.

\subsection{Data Collection}

Data collectors and supervisors were trained for two days on objective of the study, methodology of data collection, interviewing approach and data recording. Interview was conducted with women of reproductive age and where if it were impossible to get them or if there were refusals next HH was used immediately for the study. In households with more than one woman in reproductive age, one among them was selected by lottery method.

To cross check the rightness of the data going to be collected and to decide who know more about women obstetrics history, the husbands were interviewed about their current wife's obstetrics history. The questionnaire was prepared first in English and then was translated into Amharic language for field work purpose and back to English for checking language consistency. Language translation was done by language teachers.

\subsection{Data Analysis}

First the data was checked for completeness and consistency. Then it was coded and entered in the computer using SPSS version 16.0 software. Univariate, bivariate and multivariate analysis were performed. Results were presented in the form of figures, tables, graphs and texts.

\subsection{Ethical Considerations}

Ethical clearance was obtained from the Ethical Review Committee of GAMBY Collage of Medical Science and Letters for permission was obtained from Research and Technology Transfer Core Process of Amhara National Regional State then in turn from Gonji Kolella District Health office. Informed consent was obtained from the subjects involved in the study. The study subjects were informed about the objective of the study, all the reasons why they were chosen and why the research is going to be done. The participants were given the opportunity to withdraw from the study at any point in the course of the study if they wish to do so. Additionally, they were informed about the confidentiality of all the data they gave as it were seriously respected and their name were not mentioned on any information they gave.

\section{Result}

\subsection{Socio-Demographic Characteristics of Study Participants}

A total of 611 were included in the study with response rate of $98.2 \%$. The mean age of the study participants was 29.9 years (median $=28$ years) with a standard deviation of \pm 8.94 years. Above $40 \%$ of study participants were between the age of 25 and 34 years. All of participants were Orthodox Christian religion followers and Amhara ethnic group.

As portrayed in Table 1, about $76 \%$ were married and $5 \%$ were single. Above $75 \%$ of study participants were not able to read and write, around $40 \%$ of study participants had no at least one $\mathrm{HH}$ member who attend primary and above education in the family and almost $59 \%$ of husbands of study participants were unable to read and write. Sixty one percent of study participants got information about reproductive health from health workers and/or health institution and $2.5 \%$ had not any information about reproductive health.

\subsection{Obstetric History of Study Participants}

As portrayed in Table 2, the mean age at the first marriage was $13.1 \pm 4.4$ years. Around 6\% (34 women) 
Table 1. Socio-demographic characteristics of study participants in rural kebeles of Gonji Kollela District, Northwest Ethiopia, 2013.

\begin{tabular}{|c|c|c|}
\hline Characteristics & Number $(n=611)$ & Percentage (\%) \\
\hline \multicolumn{3}{|l|}{ Age group } \\
\hline $15-19$ & 60 & 9.8 \\
\hline $20-24$ & 122 & 20.0 \\
\hline $25-29$ & 148 & 24.2 \\
\hline $30-34$ & 98 & 16.0 \\
\hline $35-39$ & 73 & 11.9 \\
\hline $40-44$ & 50 & 8.2 \\
\hline $45-49$ & 60 & 9.8 \\
\hline \multicolumn{3}{|l|}{ Marital status } \\
\hline Single & 31 & 5.1 \\
\hline Married & 463 & 75.8 \\
\hline Divorced & 77 & 12.6 \\
\hline Separated & 12 & 2.0 \\
\hline Widowed & 28 & 4.6 \\
\hline \multicolumn{3}{|l|}{ Women educational status } \\
\hline Unable to read and write & 462 & 75.6 \\
\hline Able to read and write & 74 & 12.1 \\
\hline 1 - 8 grade & 47 & 7.7 \\
\hline High school and above & 28 & 4.6 \\
\hline \multicolumn{3}{|l|}{ Husband educational status } \\
\hline Unable to read and write & 340 & 58.7 \\
\hline Able to read and write & 184 & 31.7 \\
\hline 1 - 8 grade & 31 & 5.3 \\
\hline High school and above & 25 & 4.3 \\
\hline \multicolumn{3}{|l|}{ Educated household member } \\
\hline No & 210 & 39.4 \\
\hline Primary & 240 & 34.3 \\
\hline Secondary & 154 & 25.2 \\
\hline Above secondary & 7 & 1.1 \\
\hline \multicolumn{3}{|c|}{ Source of information about reproductive health } \\
\hline No source of information & 15 & 2.5 \\
\hline From the community & 38 & 6.2 \\
\hline From health workers/institution & 370 & 60.6 \\
\hline Radio/TV & 188 & 30.8 \\
\hline
\end{tabular}


Table 2. Obstetric history of study participants in rural kebeles of Gonji Kollela District, Northwest Ethiopia, 2013.

\begin{tabular}{|c|c|c|}
\hline Characteristics & Number $(n=611)$ & Percentage (\%) \\
\hline \multicolumn{3}{|c|}{ Age at the first marriage $(n=580)$} \\
\hline Below 5 year & 34 & 5.9 \\
\hline $6-10$ & 154 & 26.5 \\
\hline $11-17$ & 299 & 51.5 \\
\hline $18-23$ & 87 & 15 \\
\hline Above 24 years & 6 & 1 \\
\hline \multicolumn{3}{|c|}{ Age at the first pregnancy $(n=543)$} \\
\hline $11-15$ & 93 & 17 \\
\hline $16-20$ & 359 & 66 \\
\hline $21-25$ & 75 & 14 \\
\hline $26-32$ & 16 & 3 \\
\hline \multicolumn{3}{|c|}{ Number of pregnancies $(n=543)$} \\
\hline $1-3$ & 310 & 57.1 \\
\hline $4-6$ & 157 & 29 \\
\hline $7-9$ & 71 & 13.1 \\
\hline 10 and above & 3 & 0.6 \\
\hline \multicolumn{3}{|c|}{ Abortion history $(n=543)$} \\
\hline Yes & 57 & 10.5 \\
\hline \multicolumn{3}{|c|}{ Number of abortion $(n=65)$} \\
\hline 1 times & 57 & 87.7 \\
\hline 2 times & 8 & 12.3 \\
\hline \multicolumn{3}{|c|}{ Type of abortion ( $(n=65)$} \\
\hline Induced & 6 & 9.2 \\
\hline Spontaneous & 59 & 90.8 \\
\hline \multicolumn{3}{|l|}{ Place of abortion } \\
\hline At home & 62 & 95.4 \\
\hline At health institution & 3 & 4.6 \\
\hline \multicolumn{3}{|l|}{ Abortion care provider } \\
\hline Yourself/relatives & 62 & 95.4 \\
\hline Health professionals & 3 & 4.6 \\
\hline \multicolumn{3}{|c|}{ Complications of abortions } \\
\hline Yes & 57 & 100 \\
\hline \multicolumn{3}{|c|}{ ANC follow up history $(n=543)$} \\
\hline Yes & 329 & 60.6 \\
\hline \multicolumn{3}{|l|}{ PMTCT (n = 543) } \\
\hline Yes & 275 & 50.6 \\
\hline \multicolumn{3}{|c|}{ Family planning history $(n=611)$} \\
\hline None users & 154 & 25.2 \\
\hline Methods for spacing & 437 & 71.5 \\
\hline Permanent methods & 20 & 3.3 \\
\hline
\end{tabular}


among all married study subjects celebrated their first marriage before celebrating their $5^{\text {th }}$ birth day and above half of $(51.5 \%)$ of them celebrated their first marriage between 11 and 17 years. That means more than $84 \%$ of the study participants claimed to be married before they celebrated their $18^{\text {th }}$ birth day.

The mean age at the first pregnancy among all pregnancy experienced study participants was 18.1 years. Majority of study participants (66\%) were celebrating their first pregnancy between the year 16 and 20. From these pregnancy experienced study participants around $96.6 \%$ did not knew their RH status with husbands and all study participants those who have had RH incompatibility with their husbands $(n=3)$ were also have had history of abortion. Among all pregnancy experienced study participants 57\% have had 1 up to 3 numbers of pregnancies but only $0.6 \%$. $(n=3)$ have had 10 and more number of pregnancies. The mean of total number of pregnancies and average pregnancies intervals among all study participants was 3.2 and 2.1 years respectively.

From the total number of all pregnancies $(n=1951)$ around $95.6 \%$ were live births and $3.3 \%(n=65)$ were abortions. The Total Abortion Rate (TAR) among all pregnancy experienced study participants was $10.5 \%$ and $12.3 \%(\mathrm{n}=8)$ of women have had double abortions.

The prevalence of abortion from all pregnancy experienced study participants was $12 \%$ (spontaneous $=10.9 \%$ and induced $=1.1 \%$ ). The result also showed that $95.4 \%$ of abortions were performed at home without the help of any health professionals and only $4.6 \%(\mathrm{n}=3)$ were performed in health institutions by health professionals. All study participants who have had abortion histories were also mentioned at least one complication just after their abortion. Among all pregnancy experienced women $60.6 \%$ have had Antenatal care follow up history and the remaining $39.7 \%$ had not any Antenatal Care follow up history. Above half of pregnancy experienced women (50.6\%) have received PMTCT service.

From all study participants included in the study majority of them $(71.5 \%)$ were spacers but $1 / 4^{\text {th }}$ of study participants were none users of different types of family planning methods and the remaining $3.3 \%$ were permanent users of family planning methods.

\subsection{Outcomes of Pregnancies by Orders of Pregnancies}

The chance of giving lost births is decreased as the order of pregnancies increased from the $1^{\text {st }}$ to the $10^{\text {th }}$ and the vice versa i.e. the chance of giving lost birth is $5 \%$ for $1^{\text {st }}$ pregnancies and $0 \%$ for the $10^{\text {th }}$ pregnancies and the chanced of giving live birth is $95 \%$ for the $1^{\text {st }}$ pregnancies and $100 \%$ for the $10^{\text {th }}$ pregnancies (Table 3 ).

The finding also showed that the chance of being pregnant decreased as the orders of pregnancies increased (88.9 for the $1^{\text {st }}$ pregnancies and 0.5 for the $10^{\text {th }}$ pregnancies) which is calculated from the total study participants $(\mathrm{n}=611)$ (Figure 1$)$.

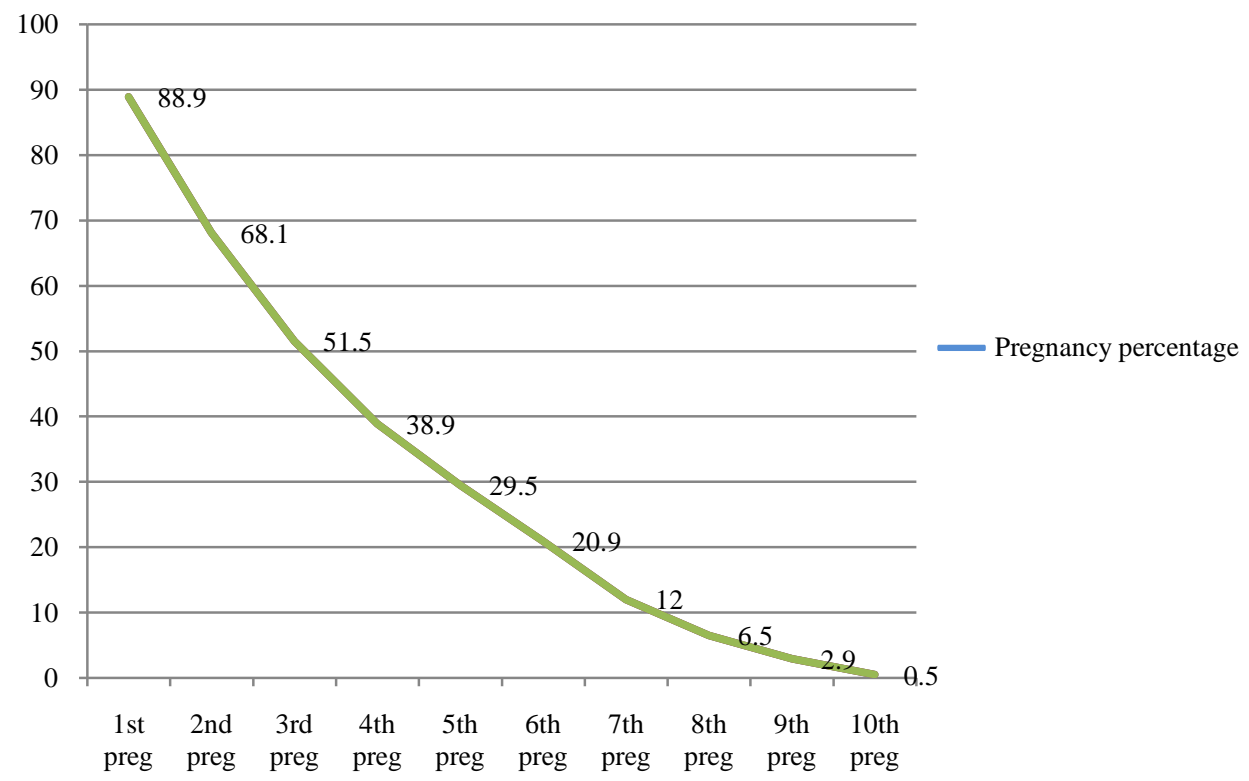

Figure 1. Graphical presentation of percentage of pregnancies by orders of pregnancies among study participants in rural kebeles of Gonji Kollela District, Northwest Ethiopia, 2013. 


\subsection{Reasons for Induced Abortions and Complications Due to Abortions}

Major complications mentioned by study participants who had abortion history were bleeding (95\%), infection (21\%) and unable to perform routine in-home and out-home activities $(100 \%)$ just after abortion up to a week duration. Reasons mentioned by study participants who have performed induced abortion were mainly socioeconomic problems like fear of parents and the public (66.7\%), lack of money and lack food for the child/absence of support (33.3\%) (Table 4). In addition to reasons for induced abortion, possible suggested reasons for spontaneous abortions were also mentioned. From these reasons mechanical movement and over load was mentioned by above half of study participants.

Table 3. Tabular presentation of outcomes of pregnancies by the order of pregnancy among study participants in rural kebeles of Gonji Kollela District, Northwest Ethiopia, 2013.

\begin{tabular}{|c|c|c|c|c|c|c|c|}
\hline & & \multicolumn{6}{|c|}{ Outcomes of pregnancies } \\
\hline & & $\begin{array}{l}\text { Live birth } \\
\text { N (\%) }\end{array}$ & $\begin{array}{c}\text { Still birth } \\
\text { N (\%) }\end{array}$ & $\begin{array}{l}\text { IUCD } \\
\text { N (\%) }\end{array}$ & $\begin{array}{c}\text { Abortion } \\
\text { N (\%) }\end{array}$ & $\begin{array}{l}\text { Total lost } \\
\text { N (\%) }\end{array}$ & $\begin{array}{c}\text { Pregnancy } \\
\text { percentage (\%) }\end{array}$ \\
\hline \multirow{10}{*}{$\begin{array}{l}\text { Orders of } \\
\text { pregnancies }\end{array}$} & $1^{\mathrm{st}} \mathrm{n}=543$ & $516(95)$ & $7(1.3)$ & 0 & 20 (3.9) & $27(5)$ & 88.9 \\
\hline & $2^{\text {nd }} n=416$ & $394(94.7)$ & $3(0.7)$ & $3(0.7)$ & $16(3.8)$ & $22(5.3)$ & 68.1 \\
\hline & $3^{\text {rd }} n=315$ & 301 (95.5) & $4(1.3)$ & $1(0.3)$ & $9(2.9)$ & $14(4.5)$ & 51.5 \\
\hline & $4^{\text {th }} \mathrm{n}=237$ & $228(96.2)$ & 0 & 0 & $9(3.8)$ & $9(3.8)$ & 38.9 \\
\hline & $5^{\text {th }} \mathrm{n}=180$ & $172(95.5)$ & $2(1.1)$ & 0 & $6(3.4)$ & $8(4.5)$ & 29.5 \\
\hline & $6^{\text {th }} \mathrm{n}=127$ & $124(97.6)$ & $1(0.8)$ & 0 & $2(1.6)$ & $3(2.4)$ & 20.9 \\
\hline & $7^{\text {th }} \mathrm{n}=73$ & $71(97.3)$ & 0 & 0 & $2(2.7)$ & $2(2.7)$ & 12 \\
\hline & $8^{\text {th }} n=40$ & 39 (97.5) & 0 & 0 & $1(2.5)$ & $1(2.5)$ & 6.5 \\
\hline & $9^{\text {th }} \mathrm{n}=17$ & $17(100)$ & 0 & 0 & $\mathbf{0}$ & 0 & 2.9 \\
\hline & $10^{\text {th }} \mathrm{n}=3$ & $3(100)$ & 0 & 0 & $\mathbf{0}$ & 0 & 0.5 \\
\hline \multicolumn{2}{|c|}{ Total $(\mathrm{n}=1951)$} & 1865(95.6) & $17(0.9)$ & $4(0.2)$ & $65(3.3)$ & $86(4.4)$ & \\
\hline
\end{tabular}

Table 4. Reasons for induced abortions and complications due to abortions from study participants in rural kebeles of Gonji Kollela District, Northwest Ethiopia, 2013.

$\begin{array}{lll}\text { Characteristics } & \text { Number } & \text { Percentage (\%) }\end{array}$

\section{Complications ( $\mathrm{n}=65)$}

$\begin{array}{lcc}\text { No complication } & 0 & 0 \\ \text { Bleeding } & 62 & 95.4 \\ \text { Infection } & 12 & 21 \\ \text { Unable to perform in/out-home activities } & 65 & 100 \\ \text { easons for induced abortion (n = 6) } & 4 & 66.7 \\ \text { Fear of parents and the public } & 2 & 33.3 \\ \text { Lack of money/food/for child } & & \\ \text { ggested reasons for spontaneous abortion (n = 59) } & 18 & 30.5 \\ \text { I don't know } & 32 & 54.2 \\ \text { Mechanical movement and over load } & 9 & 15.3 \\ \text { Psychological stress and frustration } & \end{array}$




\subsection{Association between Abortion History and Selected Characteristics of Study Participants}

Bivariate logistic regression was done on each socio-demographic and obstetric history related variables. Variables that fulfill the requirement $(\mathrm{P}$-value $<0.2)$ were tried to analyzed and used for multivariate logistic regression analysis but among all selected variables no variable was meet this significance level. Due to this, variables those have had P-value $\leq 0.3$ were selected and analyzed for multivariate logistic regression analysis. Except only four variables all other variables were not fulfilled this significance level. These variables were age group, marital status, women's educational status, presence or absence of educated HH members in the family (Table 5).

Back ward stepwise logistic regression analysis which takes the effect of confounding into account was utilized. All four variables which have had P-value $\leq 0.3$ in the bivariate analysis were included in the back ward step wise multiple regressions. Except educational status of study participants (P-value $=0.023$ ) the remaining three variables were not showed statistically significant association with abortion history. The multivariate logistic regression analysis of this study showed that as the educational status of study participants increased, there were an increased in number of study participants who have had abortion histories. Particularly, among the total study participants, those who had primary and above education were 2.4 times to have had abortion histories compared to study participants those who have had below primary educational status $[\mathrm{P}$-value $=0.023, \mathrm{AOR}=$ $2.4,95 \% \mathrm{CI}=1.13-5.10]$ (Table 6).

\section{Discussion}

The major objective of this study was to assess prevalence, and correlates of abortion among rural communities in Gonji Kolela District. The unique aspect of this study was that it was able to incorporate selected obstetric histories especially maximum number of pregnancies and outcomes of these pregnancies.

The present study revealed that the overall prevalence of abortion was $12 \%$ (spontaneous $=10.9 \%$ and induced $=1.1 \%)$. This indicates that almost $90.8 \%(n=59)$ of abortions were spontaneous and the remaining $9.2 \%$ $(n=6)$ were induced abortions. This is in line with a study done in our region wherein it was reported that $91 \%$ of the abortions were spontaneous [18]. The finding of another community based study some 17 years ago revealed the same trend. They reported that prevalence of spontaneous abortion is higher in rural community than urban community while the prevalence of induced abortion is lower in rural community than urban community [19]. Institution based studies in Ethiopia revealed also that more than 7\% of abortion were spontaneous [14] [17] [19]. This finding is also supported by a study done in Nigeria wherein it was reported that induced abortion rate was lower among the poor rural regions than among the more economically developed regions [13].

A study of the magnitude of abortion in rural Gondar, northwest Ethiopia, revealed that more than $95 \%$ of abortions were performed at home without the help of any health professionals and all study participants who have had abortions ended up with at least one type of post abortion complications. This indicates that all abortions were unsafe. Our finding was in line with this report. These findings from Northwest Ethiopia are supported with WHO reports [1] [2].

This study also revealed that majority of abortions occurred during the early pregnancies i.e. as the orders of pregnancies increased the chance of study participants giving abortion were decreased (3.9\% for the $1^{\text {st }}$ and zero for the $10^{\text {th }}$ pregnancies). The study conducted in Adet and Dabat districts also showed that with the increase in age and number of pregnancies there was a decrease in number of mothers who had induced abortions [8].

The findings of this study also showed that among mentioned socioeconomic problems that contribute for induced abortions, $3 / 4^{\text {th }}$ of participants were due to fear of parents and the public and the remaining $1 / 4^{\text {th }}$ were due to lack of money, food and support for the child. The study conducted in Adet and Dabat districts also showed that majority of reasons were due to fear of the family/community (31\%) followed by to avoid school interruption (27\%) and due to financial problem (14\%). This indicates that socioeconomic problems were the main reasons to perform induced abortions among rural pregnant women [21].

Among possible suggested reasons mentioned by participants who have had spontaneous abortions, more than $50 \%$ of them (54\%) associated abortion to wrong mechanical movements and over load. These reasons showed that pregnant women in the study area were did not know their early pregnancies and they did not give appropriate care for themselves during early pregnancies, or were subjected to inevitable work overload. Fifteen percent of participants who have had spontaneous abortions said that their abortions were due to psychological stress 
Table 5. Bivariate analysis indicating association between abortion history and selected characteristics of study participants in rural kebeles of Gonji Kollela District, Northwest Ethiopia, 2013.

\begin{tabular}{|c|c|c|c|c|}
\hline \multirow{2}{*}{ Characteristics } & \multicolumn{2}{|c|}{ Abortion history } & \multirow{2}{*}{ COR (95\%CI) } & \multirow{2}{*}{ P-value } \\
\hline & Yes $(n=57)$ & No $(n=554)$ & & \\
\hline \multicolumn{5}{|l|}{ Age of women in years } \\
\hline $15-19$ & 3 & 57 & 1.00 & \\
\hline $20-24$ & 12 & 110 & $2.1(0.56-7.64)$ & 0.27 \\
\hline $25-29$ & 16 & 132 & $2.3(0.65-8.21)$ & 0.20 \\
\hline $30-34$ & 11 & 87 & $2.4(0.64-9.00)$ & 0.20 \\
\hline $35-39$ & 7 & 66 & $2.0(0.50-8.20)$ & 0.33 \\
\hline $40-44$ & 4 & 46 & $1.7(0.35-7.76)$ & 0.53 \\
\hline $45-49$ & 4 & 56 & $1.3(0.29-6.34)$ & 0.70 \\
\hline \multicolumn{5}{|l|}{ Marital status } \\
\hline Single & 0 & 31 & $0(0.00)$ & 1 \\
\hline Married & 47 & 416 & $3.0(0.41-23.0)$ & 0.28 \\
\hline Divorced & 8 & 69 & $3.1(0.37-26.2)$ & 0.29 \\
\hline Separated & 1 & 11 & $2.5(0.14-42.8)$ & 0.54 \\
\hline Widowed & 1 & 27 & 1.00 & \\
\hline \multicolumn{5}{|l|}{ Women educational status } \\
\hline Below primary education & 47 & 489 & 1.00 & \\
\hline Primary and above & 10 & 65 & $1.6(0.77-3.32)$ & 0.21 \\
\hline \multicolumn{5}{|l|}{ Husband educational status } \\
\hline Below primary education & 44 & 423 & $1.1(0.55-2.00)$ & 0.89 \\
\hline Primary and above & 13 & 131 & 1.00 & \\
\hline \multicolumn{5}{|l|}{ Educated HH members } \\
\hline No & 16 & 194 & 1.00 & \\
\hline Yes & 41 & 360 & $1.4(0.76-2.53)$ & 0.29 \\
\hline \multicolumn{5}{|c|}{ Source of info. about reproductive health } \\
\hline No & 1 & 14 & 1.00 & \\
\hline Yes & 56 & 540 & $1.45(0.19-11.2)$ & 0.72 \\
\hline \multicolumn{5}{|l|}{ Family planning history } \\
\hline None-users & 12 & 142 & 1.00 & \\
\hline Spacers & 42 & 395 & $1.2(0.60-2.30)$ & 0.63 \\
\hline Permanent users & 3 & 17 & $1.9(0.50-7.6)$ & 0.33 \\
\hline
\end{tabular}

Table 6. Multivariate analysis indicating association between abortion history and selected characteristics of study participants in rural kebeles of Gonji Kollela District, West Gojjam Zone ANRS, Northwest Ethiopia, 2013.

\begin{tabular}{cccccc}
\hline \multirow{2}{*}{ Characteristics } & \multicolumn{2}{c}{ Abortion history } & & & \\
& Yes $(\mathrm{n}=57)$ & No $(\mathrm{n}=554)$ & & & \\
Women educational status & & & & & \\
Wnalue & & & \\
Unable to read and write & 47 & 489 & 1.00 & 1.00 & \\
Primary and above & 10 & 65 & $1.6(0.77-3.32)$ & $2.4(1.13-5.10)$ & $0.023^{* *}$ \\
\hline
\end{tabular}


and frustration. WHO also said special care and concern should be given for pregnant women in developing countries to overcome the problem of death due to unsafe abortion. Unlike the above suggested reasons, about $30 \%$ of study participants who have had spontaneous abortions could not mention any possible reasons for their abortions.

All study participants who have had abortions in this study were not able to perform in-home and out-home routine activities for week's duration. More than 95\% were faced with bleeding and around $21 \%$ reported infections. The World Bank 2007 report also indicated that burden of unsafe abortion lies not only with the women and families but also with the public health system. Survey of unsafe abortion conducted in 15 hospitals of Ethiopia showed that infection (28\%), genital tract injury (12\%) and abortion deaths (1.2\%) were major post abortion complications [14].

The study conducted in Adet and Dabat districts showed that study participants who have had elementary education were 3.3 times most likely to have abortion compared to those unable read and write. This study also showed that study participants those who have had primary and above education were 2.4 times most likely to have had abortion history compared with those who have had educational status below primary [21].

The study has the following limitations. Major segment of study participants were from rural area with low educational attainment. So, recall bias can be high or even they might lot like to be remembered about their bad experiences following abortion so that they would report abortion as a result prevalence abortion could be undermined.

\section{Conclusion}

Abortion is high among rural women. Mechanism should be devised to educate the community about care to pregnant women. Why abortion is high among women who have visited school warrants further research.

\section{Acknowledgements}

The authors are grateful to Bahir Dar University, GAMBY College of Medical Sciences, all study participant, data collectors and supervisors of the study.

\section{Conflict of Interests}

Authors declared that they have no conflict of interests.

\section{Author's Contribution}

GM, MG conceived and designed the idea, analyzed the data and wrote the manuscript. RB and AN revised the research design and data analysis, prepare and critically reviewed the manuscript. All authors read and approved the final draft of manuscript.

\section{References}

[1] World Health Organization (1998) Unsafe Abortion: Global and Regional Estimate of Incidence and Mortality Due to Unsafe Abortions. 3rd Edition, WHO, Geneva.

[2] World Health Organization (1994) Abortion: A Tabulation of Available Data on the Frequency and Mortality of Unsafe Abortions. 2nd Edition, WHO, Geneva.

[3] Population Information Program, Centre for Communication, The Johns Hopkins School of Public Health (1997) Population Report, USA.

[4] Family Care International and Interagency Group for Safe Motherhood (1997) The Safe Motherhood Action Agenda: Priority for Next Decade.

[5] Ldipo, O. (1990) A Unsafe Abortion in the Third World. World Health, April-May.

[6] Lema, V., Kannau, S. and Rogo, K. (1998) Epidemiology of Abortion in Kenya. Centre for the Study of Adolescents, Nairobi.

[7] Mbizvo, M.T., Fawcus, S., Lindmarj, G. and Nystrom, L. (1993) Maternal Mortality in Rural and Urban Zimbabwe: Social and Reproductive Factors in an Incident Case-Referent Study. Social Science and Medicine, 36, 1197-1205. http://dx.doi.org/10.1016/0277-9536(93)90240-5 
[8] Anate, M., Awoyemi, O. and Petu, O. (1995) Procured Abortion in Ilorin, Nigeria. East African Medical Journal, 72, 386-390.

[9] Central Statistical Agency, Government of Ethiopia, Addis Ababa (2011) Central Statistics Authority Demographic and Health Survey Preliminary Report. Addis Ababa, Ethiopia.

[10] Federal Ministry of Health of Ethiopia (2008) The National RH Implementation Plan and Cost (First Draft). Government of Ethiopia, Addis Ababa.

[11] World Bank (2007) Capturing the Demographic Bonus in Ethiopia: Gender, Development, and Demographic Actions. World Bank, Washington DC.

[12] Mote, C.V., Otupiri, E. and Hindin, M.J. (2010) Factors Associated with Induced Abortion among Women in Hohoe, Ghana. Africa Journal of Reproductive Health, 14, 115.

[13] Henshaw, S.K., Singh, S., Oye-Adeniran, B.A., Adewole, I.F., Iwere, N. and Cuca, Y.P. (1998) The Incidence of Induced Abortion in Nigeria. International Family Planning Perspectives, 24.

[14] ESOG (2002) Survey of Unsafe Abortion in Selected Health Facilities in Ethiopia. ESOG (Ethiopian Society of Obstetricians and Gynecologists).

[15] Kebede, S., Jira, C. and Mariam, D. (2000) A Survey of Illegal Abortion in Jimma Hospital Southwestern Ethiopia. Ethiopian Medical Journal, 38, 35-42.

[16] Abdella, A. (1996) Demographic Characteristics, Socioeconomic Profile and Contraceptive Behavior in Patients with Abortion at Jimma Hospital, Ethiopia. East African Medical Journal, 73, 660-664.

[17] Melkamu, Y., Enquselassie, F., Ali, A., Gebresalassie, H. and Yusuf, L. (2003) Fertility Awareness and Post-Abortion Pregnancy Intention in Addis Ababa, Ethiopia. Ethiopian Journal of Health Development, 17, 167-174.

[18] Getahun, H. and Berhane, Y. (2000) Abortion among Women in North Ethiopia. International Journal of Gynecology Obstetrics, 71, 265-266. http://dx.doi.org/10.1016/S0020-7292(00)00279-4

[19] Senbeto, E., Alene, G.D., Abesno, N. and Yeneneh, H. (2003) Prevalence and Associated Risk Factors on Induced Abortion in Northwest Ethiopia. Ethiopian Journal of Health Development, 19, 37-44.

[20] Gonji Kollela District Administration Office (2012) Ethiopian Budget Year Annual Report.

[21] Gonji Kollela District Health Office (2012) Ethiopian Budget Year Annual Report. 